\title{
Ideal que não envelhece ${ }^{(*)}$
}

\section{A. de Sampaio Doria}

A distinção singular, com que me aplaude a Congregação desta Faculdade, onde aprendi é professo, e, mais, a escolha, para seu intérprete, de meu dileto amigo, orador fluente e eloqüente, êste encantador Soares de Mello, excedeu a quantos aplausos possam aspirar os que, como eu, hão de lidar, por força do destino, até os últimos dias da vida. Eu já não mais contava subir à cátedra, para insistir em ideas e princípios, que os velhos não mudam. A fragilidade do coração insinuava-me a prudência do repouso e do silêncio. Mas a fé no ideal que me semeou de estrelas o horizonte, não se compadece com a tibieza dos acomodados, ou a inércia dos que apenas vegetam, como quem, embora exista, não vive.

Deixai-me, pois, senhores, mais uma vez, para agradecervos, dizer em público de minhas esperanças, de minha teima, de minha fé na força imanente e criadora do ideal, que, em certas almas, não perece nunca. Nos moços, a sinceridade tem qualquer cousa de ingenuidade, que se respeita: são ambas simples e descuidadas. Mas, nos velhos, são, por vezes, ambas intransigentes e irredutiveis.

Nos projetos que me suavizaram de sonhos a mocidade, jamais figurou o de posições políticas. Indole avessa ás acomodações partidárias, não me poderia o destino sur-

(*). Discurso proferido a 14 de novembro de 1946, em agradecimento pela homenagem prestada pela Cơngregação da Faculdade de Direito. 
preender tanto, como o convite que, na manhã seguinte á vitória de 29 de outubro, me veio subtrair ao remanso de meus estudos, para assumir o ministério da Justiça, em hora de tamanha gravidade para o Brasil. Nunca me julgara talhado, para resolver, nos estilos da praxe, os problemas políticos, que se haviam de suscitar e atropelar. E, por isso, recusei com firmeza aceitar o posto que me era conferido.

Apelaram para minha qualidade de professor de direito, para o idealismo por que andara sempre enamorado, para meu patriotismo, que não podia esmorecer na hora da prova. Nada me demovia, senão quando ouvi a palavra profética de um oficial de alta patente militar, a quem me haviam apresentado ali.

Indagando êle de mim se era exata, como lhe constara, minha recusa, obtemperou, num louvável intuito de cooperação amável: "Se os senhores, os civis, não conseguem organizar o governo, não se queixem, se nós, os militares, tomemos conta dêle." A isto lhe acudi, então, sem demora: - "neste caso, sou o ministro da justiça".

$\mathrm{E}$ assim vi rasgarem-se, deante de mim, horizontes propícios a certos princípios que andei ensinando aos moços desta Casa.

Eu não sabia usar de artifícios. Não me agrada calar o que penso, nem costumo dissimular intenções. Prefiro pensar em voz alta. Nunca lidára com as subtilezas dos partidos, em suas paixões na luta pelo poder. Habituárame, ao contrário, desde criança, ouvindo aos meus, que, quando um homem se desdobra em doị ou mais, é que nunca foi nenhum. Incompreensível arvorar-se alguem, em política, desabusado e falso, e, ao mesmo tempo, como particular, exemplo de elegância moral aos filhos.

$\mathrm{Na}$ intransigência desta filosofia a que me habituára, seria prudente ter o governo por ministro criatura sempre igual a si mesma? 
Desconfiado, embora, de minha resistência física, confiei sem temor no poder do ideal que revigora corações. Emquanto sentia comigo a razão, nenhuma importância dei á grita deselegante dos interessados, ao desapontamento dos levianos, e, até, ameaças de potentados. O que importava para mim, e com que satisfação, era abrir caminho, por entre os entulhos da ditadura deposta, para redemocratizar o pais, reavivando-lhe a consciência de que é o soberano. Não havia tempo de perder.

Nunca, porém, poderia eu imaginar tão benevolente repercussão, nesta Casa, do que andei fazendo, em tão pouco tempo, no ministério da justiça, deste pobre pais.

Eu sempre tive como certo que, para se promover, neste mundo, alguma cousa que valha, trếs predicados precisam estar reunidos: a convicção dla verdade, a consciência do dever, e a intuição do senso comum.

\section{A convicção da verdade}

A convição da verdade não é a leveza dos que se improvisam, e se presumen. Mas, em cada qual, a formação lenta de toda uma vida de observação e de estudo, no sector restrito, a que se havia dedicado. E não duvide nenhum moço do futuro sonhado, que o espera, se souber, desde cêdo, perseverar no trabalho, metódico e paciente, da especialidade que preferir. A convicção das verdades, que haja adquirido, lhe dará confiança em si mesmo, indiferente e sereno ao croachar da bicharia rasteira dos brejos.

Mas cuidado! A verdade é de si mesma esquiva e fugidia. Nada de contentar-se com aparências, nem jamais blasonar-se de sábio. A suprema sabedoria está em saber que, quanto mais se aprende, mais se fica sabendo, afinal, que se ignora quasi tudo. E o pouco que se logre saber, só é convicção da verdade, depois de aparado, ao fogo da dialética, em debates irrestrictos. 
Mesmo assim, quantos enganos, quantas desilusões sempre que as observações, deem de hombros aos processos lógicos de inferência; ou porque faltasse o observador à imparcialidade e, ainda por desdem à probidade científica de ir o investigador até onde o conduza a interpretação dos factos observados.

Pois, meus amigos, levei daqui, para o ministério da justiça, convicções firmes concepções que tenho por exatas, ideais de justiça, como fachos de luz no caminho que ia trilhar.

\section{A verdade democrática}

Uma destas convicções é a de que a democracia é nem mais, nem menos que a responsabilidade. Eleição dos que governem, pelos governados capazes de escolher com acêrto. $\mathrm{E}$ responsabilidade dos governantes no desempenho do mandato. Não só eleger. Deixará de existir a democracia, se não puderem os governados chamar a contas, nas urnas os governantes que elegeram. Esta, a minha convicção da verdade democrática, que não cessei de recomendar principalmente aos moços desta Faculdades.

Daí o combate que dei, intransigente e sem tréguas, ao custeio das eleições de 2 de dezembro pelos Estados, ou pelos Municipios. Quem não sabe que valer-se alguem de seu cargo, para proteger correligionarios ou perseguir desafetos, é usurpar o logar em que está? Quem ignora que gastar o governo, em eleições de sua parcialidade, dinheiro, subtraido em impostos ao suor do povo, como em publicidade partidaria, é cometer peculato?

Ouvi que estas ideas são extranhas ou novas. Novas, porque em desuso. Mas não corresponderão acaso, à verdade?

Não menos inflexivel o combate que traveì, embora com resultados mínimos, á venalidade e á coacção eleitorais. Voto por interesse, ou sem liberdade, toda gente sabe que 
é a mais ignobil farça da democracia. Só o voto secreto desarma a corrupção, com inutilizar a venalidade, e anular a intimidação. Foi o que sempre arrazoei ao povo, desde os tempos heróicos da "Liga Nacionalista", que esta Faculdade fundou, dirigiu e manteve.

Realisar, então, uma eleição presidencial, em todo o país, com o voto secreto, para que o eleitor fosse livre, e, mais, com a apuração judicial, para que fosse ineqüívoca a verdade na contagem dos votos, e certa a justiça na proclamação dos eleitos, a que melhor experiência e prova poderiam submeter-se os ideais que vinhamos pregando?

\section{A consciência do dever}

Sob a consciência do dever, nada poderá deter o homem sincero comsigo mesmo. As trapaças e promessas vãs, as manhas e as tortuosidades, eram tudo isto a escola política entre nós. Mas eu não havia frequentado os bancos dessa escola, que sempre tive por diabólica. Não creia ninguem que a salvação das aparências jamais salvasse a decência dos atos.

Nem creia ninguem na estabilidade das instituições sociaes, quando se substituem as leis eternas da política, pelos artifícios da felonia.

Eis por que não tive dúvidas em seguir os princípios da boa política. 'A oportunidade era de encomenda. Perdela ou malbarata-la seria estultícia. O dever era tomar iniciativas oportunas e certeiras de combate às fraudes nas eleições. E quem não se sentiria honrado em lhe assumir a responsabilidade?

o que se fez, digam os outros. Mas, desde logo, uma cousa não se podé negar: é que as eleições foram verdadeiras, honesta a apuração dos votos, e correta a proclamação dos eleitos. 
Certamente, o corpo eleitoral foi habilmente preparado pela ditadura, para que prevalecesse, nas urnas, a maioria dos mandados, sem elevação de pensamento, sem inspiração do futuro, vasio o coração do ideal da pátria. Isto era sabido. Mas não se podia, sequer, pensar no adiamento das eleições, tão sagrados eram os compromissos morais das forças armadas para com a Nação.

Apezar dos tropeços, que não faltaram, a consciência do dever, que nos animava, foi a rígida couraça, onde se vinham quebrar os dentes á maledicência dos contrariados, às calunias e às mentiras da raça dos réprobos, que nunca deixaram de existir. Passei, indiferente, á incompreenção de uns, e, desdenhoso á maldade de outros. Não atendi a pedidos por interêsse de qualquer partido, ainda quando vindos de eminências. Por cousa nenhuma, haviamos de, quebrar a imparcialidade. E, sem sangue, sem distúrbios, sem incidentes de monta, as eleições de 2 de dezembro enobreceram o Brasil.

\section{Instituição do senso comum}

Se sem fé no dever, nada se faz que fique, não ha o que desesperar, quando nos ajude o senso comum.

Já se tem dito que senso comum é o que ha de menos comum entre os homens. O que mais agrada á massa, são os fogos de artifício, que reluzem, acrobacias idealógicas de romances, ares de grandeza que maravilhem. Mas, no governo dos povos, estas maravilhas são maravilhas inúteis. Vale mais a intuição do bom senso no equilíbrio das idéas, no cabimento da técnica, e na oportunidade da ação.

Quem logre reunir em si esses tres elementos, e queira sem transigências, e saiba o que quer, se tiver a paixão da verdade, e o respeito a si mesmo, nada terá de que se arrepender. Só onde o dever se houver por mercadoria, onde a verdade se confundir com aparências, e onde o es- 
pírito de novidades empanar o bom senso, é que tudo vae à garra, por força de gravidade moral.

Melhor exemplo não se tem da falta de senso, do que um extranho espirito novo, que anda na moda, e se anuncia. A grande novidade é que os tempos são outros. Falase em remodelar o mundo de alto a baixo nas idéas, nos sentimentos, nos costumes. Ao sôpro do vendaval que vem do Oriente, apegar-se alguem a sombras do passado, o de que menos se lhe argue, é de cegueira reacionária, antigualha que rescende o môfo. Não é outro o pregão que anda de boca em boca, como a era nova que se aproxima.

\section{Principios constitucionais}

Màs, 'não é de novidades que se tece a constituição de um povo. Os institutos jurídicos e os principios políticos, que a estructurem, são imutáveis e eternos. Veja-se, por exemplo, a organização política da Inglaterra desde tempos quase imemoriais, e cujas bases não aluem, não estremecem, não se modificam nem sob o terremoto da guerra de extermínio, que acaba de vencer, para salvação do mundo. A garantia do hábeas corpus, sob cujo pálio mais de trinta gerações têm sobrenadado aos abusos do poder, vem desafiando a passagem corrosiva dos séculos que tudo destroem. Qualquer inovação que se ousasse, na finalidade do hábeas corpus, e na rapidez, com que acode a vítimas de ilegalidades, seria fatal ao império do direito entre os homens. No princípio de que não deve o povo imposto que não tenha votado, ninguem admite, na Inglaterra, a menor alteração; e foi, provocadas pela defesa dêle que proclamáram sua independência as 13 colônias que se fizeram em Estados Unidos.

$\mathrm{E}$ que ha, nos tempos novos, com vantagem sobre êsses dois princípios democráticos? 
Apezar de suas vinte e poucas emendas, a Constituição dos Estados Unidos é sémpre a mesma, ha mais de seculo e meio.

Que é o que pode substituir a separação perfeita de poderes que, ali, se pratica? Que é o que pode superar a declaração dos direitos do homem, que, dois anos antes da Revolução francêsa, já naquele monumento juridico, se estatuia? Nada pode haver de melhor, para equilibrar a liberdade, que nada cede, com a autoridade que não fraqueia.

As eleições quadrienais, pelo povo, do chefe do governo, e as eleições, de dois em dois anos, dos deputados federaes na grande Nação do Norte, realizam, com sabedoria jamais igualada, os dois princípios que substanciam a democracia. Qual a novidade, entre as que se anunciam, capaz de substituir este sistema de composição e responsabilização do público em face da liberdade e dos direitos do homem?

Trarão, acaso, os novos tempos alguma cousa equiparavel ao voto secreto, para resguardar o eleitor contra a venalidade e a intimidação? $O$ voto público, que se desse em trôco, seria, não novidade, mas velharia, já sepultada, ha muito, no cemitério das ignomínias políticas.

Que é, por fim, o que se pode comparar, em garantia, á da Constituição norteamericana contra o despotismo da plebe, ou a tirania dos governos, contra os abusos, em suma, de poder, seja qual fôr a origem que tenha? Foi a suprema creação do gênio político, a maravilha que assombra, e é tão simples, verdadeiramente a ordem nova, que, por inspiração divina, ali se instalou, para honra da humanidade. Que é, reitero, o que podem os miseráveis tempos atuais trazer de mais viril, de mais venturoso, em confronto com a defeza judiciária dos direitos da liberdade, como se prescreveu na constituição dos Estados Unidos?

O principio da federação, o da separação de poderes, o da limitação da competência do Congresso, e atribuições do Governo, o do voto secreto e proporcional, o da brevi- 
dade do mandato politico, o da liberdade de pensamento e crença, o da pluralidade de partidos, o de viver cada qual como haja por bem, e não como pareça melhor aos outros, o de garantia ao homem do que lhe que produz o trabalho, são todos principios liquidos e limpidos da civilização politica. Aperfeiçoa-los é sempre possivel, mas ignora-los, amesquinhá-os, ou substitui-los, isto é o que não se pode admitir, e mal se concebe. Uma constituição emenda-se, acrescenta-se, aperfeiçoa-se. Mas, trocar um povo uma por outra, por amor de novidades, é, antes de tudo, inconsciência do abismo que cava sob seus pés. Quando a França de 1789, andou forjando e trocando constituições, não teve tranquilidade nem segurança. Nenhuma das constituições imaginadas se estabilisou. Só com o desastre de 1870, quando, em vez de ainda outra constituição, se conciliou com o bom senso, tão amadurecido no povo inglez, promulgando duas ou tres leis rápidas de organização dos poderes, a França pôde gosar largo período de prosperidade na paz. Os Estados Unidos jamais substituiram a constituição de 1787, nem mesmo para curar as feridas da mais sangrenta guerra civil, que já o mundo viu, a da separação de 1863 a 1865. Nós, ao contrário, como na fantasia gaulêsa, abjuramos a maravilhosa constituição de 1891, para nos espraiarmos na de 1934, logo posta a margem pela de 1937, e agora não se sabe o que virá.

Estamos, em verdade, numa encruzilhada do destino: ou conservaremos o que já tinhamos de bom e sadio, melhorando; ou adotaremos novidades de importação, e ninguem sabe que futuro nọs aguardará.

Uma constituição, como a da América do Norte, ou dos costumes inglêses, é um corpo de leis, no sentido rigoroso da ciência: relações necessárias entre causas e efeitos. A causa global é o aparelhamento de uma autoridade forte, e o efeito massiço, que decorre desta causa, é o respeito geral às liberdades iguaes. Tais institutos devem constituir 
o poder público, que deles flua, em consequência, poderem os indivíduos fazer, ou deixar de fazer tudo o que não destrua a sociedade, nem lhe enbarace o desenvolvimento. A relação entre aqueles institutos e a ordem jurídica, que lhes resulte, é lei, como outra qualquer, nos vários setores da ciência. Os processos políticos na Inglaterra e nos Estados Unidos, de preferência, hoje, a quaisquer outros, como outrora, na Grécia ou no Império Romano, valem por experiências criadoras, no laboratório vivo das sociedades humanas. Alí, se aprende a ciência do direito público, como Pasteur aprofundou seus conhecimentos de biologia nas observações que fez, e experimentações que promoveu. E tudo causa e efeito, antecedentes que atuam, para consequentes que virão. 'A constância da natureza é tanto nos fenômenos biológicos, como nos fenômenos sociaes. Se umạ constituição adotar normas opostas ás de que a experiência já demonstrou a eficácia, a catástrofe não se fará esperar. A história dos povos são experimentações politicas, em que a humanidade já devia ter aprendido a ter juizo. Conhece, pelo menos, a lei suprema no destino das sociedades, a de que a legitimidade do poder é a matriz de estabilidade das instituiçõôs politicas, e, pois, a ilegitimidade a fonte perpétua das conspirações e das guerras civis.

\section{Experimentações sociais}

Dai, o senso comum de que, quando se haja experimentado uma constituição realista como a de 1891, é incrivel que, em logar de emendá-la nos pormenores que falharam, adaptando-a a novos ensinamentos, seja posta de lado, para fabricar outra sem os Institutos que a sublimam. Lembra sob o aspecto teórico, a fantasia de fazer alguem em qualquer ciência, tábula raza das leis tão penosamente formuladas, para substitui-las em nome de novidades, por hipoteses que a experiência desautorise. E seria, sob o as- 
pecto humano, a criminosa aventura de experimentar em carne viva, com as decepções e desgraças irreparáveis que virão.

\section{Consequencias marxistas}

Nos tempos novos, a hipótese que avulta e ameaça subverter tudo e todos, é o marxismo, que o leninismo, transformou em politica do Estado.

Sabe o povo, realmente, o que é o marxismo com que lhe acenam a canaan da redenção e da fartura? Observou o povo o que está em vigor no único pais que o chamou a si? Suspeita, acaso, de quais sejam as consequências fatais da socialização da riqueza, e pois, de onde só o governo é empregador?

Perguntae-o a qualquer fanático desta ideologia extravagante, e verificareis o desconsolador antagonismo entre o que pense, e a crúa realidade dos fatos. O marxismo, ou comunismo, se resume nestes tres princípios de governo: a ditadura do proletariado, a socialização do capital, e a insegurança juridica.

A socialização do capital é a proibição de ter um homem outro homem a seu soldo. Só ha um empregador, e esse é o Estado, ou o governo. Todos os indivíduos vivem, queiram ou não, em seu pais, como detentos em uma penitênciária agrícola ou industrial. Dentro de seus muros, os presos vivem soltos, como, dentro no pais de regime comunista, os seus habitantes.

Se alguem deixa o emprego, só o governo lhe pode dar outro, e, como este dirige tudo e todos, determina êle, sem apêlo, onde pode cada qual trabalhar. Quem não obedecer, fica desempregado, e, como quem não trabalha não come, a fome coloca a todos entre as tenazes do dilema: não sair do emprego onde está, ou morrer de fome.

Para não verem com olhos de vêr, a propaganda deslumbra a vista com a miragem das reivindicações prole- 
tárias. A massa popular se deixa facilmente ofuscar por palavras de esperança para a riqueza, por promessas de fartura sem trabalho, e pelo assanhamento da luta para satisfação dos instintos que dormen. É assim que os tempos modernos querem as novas constituições.

\section{Homens providenciais}

Bemaventurados, porém, os povos que logram contar, em momentos excepcionais de sua história, com homens providênciais, como os patriarcas da Nação Americana em 1787, e o da República no Brasil em 1891.

Não ha, hoje, no Brasil, na desorientação geral dos espiritos, lugar para mais de duas atitudes, para mais de duas decisões, para mais de dois partidos políticos. Do alto da cordilheira, onde se descortina o futuro vago, indeciso e cheio de surprezas, envolto em mistérios, duas ideologias que se repelem, dominam o cenário sem competições.

De um lado, a democracia, e, em consequência, a pluralidade dos partidos; e, de outro lado, a ditadura do proletariado, e, em consequência, um só partido.

De um lado, a liberdade e a justiça do trabalho, como prerogativa que distingue o homem das féras; e, de outro lado, a socialização do capital, de sorte que não haja empregador, senão o Estado, com o monopólio das atividades produtivas, na industria, no comércio, na agricultura, nos bancos.

De um lado, por fim, a segurança juridica; e, de outro lado, nenhuma garantia individual, deante do poder, sem limite na lei, nem no direito de outrem.

São as duas perspectivas supremas, com que se defronta, hoje, o destino dos povos. Deante delas, não ha lugar para os atritos, as represálias, ou desidios entre os defensores da liberdade e do direito. 
Quando um pais está invadido por exércitos inimigos, só uma preocupação o domina: a defesa comum contra o Invasor armado. As dissenções da politica interna, que dividem o povo, que inimisam grupos, que irreconciliam pessoas, são accessórios, cuja liquidação ou se deixa para quando o pais estiver a salvo, ou se fará o jogo do inimigo, que passará logo todos a fio de espada.

Este, hoje em dia, o quadro político do Brasil, como o de todos os paises sem tradições de cultura. Nos paises de tradições de liberdade e autoridade á inglêsa, não é eminente o perigo da escravatura geral. Ressalvadas porém, estas nações previlegiadas, acha-se hoje o mundo sob o gládio de um imperialismo disfarçado em reivindicações das massas.

E ha de a democracia, por lhe estar, no cerne, o amor da liberdade, cultivar ela mesma, em seu seio, os germens insidiosos, que lhe envenenam as entranhas, e a sepultem por fim?

Mãos á obra, mocidade de minha terra! Pelo direito, que enobrece a pessoa humana; pela justiça, que embeleza a vida; pela civilização cristã do mundo, que nos salvará todos. Não fique ninguem indiferente, ou displiscente, senão a postos pelo direito do voto a todos os homens capazes e livres. Não representem nunca mais, os moços, mesmo os desta Casa, o sombrio espetáculo, que aquli mespo já se viu, de propagandas liberticidas, seja qual fôr a côr que as extreme. A mocidade é, como Castro Alves, o vosso poeta, por índole rebelde á escravidão, ás imposições injustas, ás prepotências sem temer o que vier. Como se explica, então, o eclipse com que andou aderindo a ditaduras, da direita, e da esquerda? Foi provavelmente um pesadelo que passou um andaço, uma epidemia moral debelada. As tradições desta Casa vivem de venerações ao direito. Aqui, não ha lugar para reivindicações senão da liberdade. Mãos á obra, para glória vossa, mocidade de São Paulo. 